\title{
El interés jurídico protegido en el delito de corrupción privada en Colombia. Análisis de contexto y conexiones con el derecho de la competencia desleal* Protected legal interest in private corruption felony in Colombia. Systematic analysis and connections with the unfair competition law
}

\section{Fernando Jiménez Valderrama** Lourdes García Rodríguez ${ }^{* * *}$}

\section{RESUMEN}

La corrupción es un problema importante para las sociedades contemporáneas latinoamericanas y particularmente colombiana. Este problema debe solucionarse desde distintas perspectivas y utilizando instrumentos en los ámbitos de la gobernanza empresarial, el derecho publico y el derecho privado. Desde los años noventa, organismos internacionales han creado reglas para combatir la corrupción privada, en las que recomiendan perseguir estos comportamientos a través de la vía penal. En Colombia, una reforma del Código Penal creó el delito de corrupción privada en 2011, que protege no sólo los intereses privados de las empresas, sino también intereses públicos en la preservación de la libertad de mercado.

PALABRAS CLAVE: Interés juridico en delitos de corrupción privada, corrupción en Colombia, delito económico, libertad de mercado, competencia desleal.

\section{ABSTRACT}

Corruption has revealed as a big problem in Latin-American and Colombian modern societies. This problem must be solved using several tools from corporation governance, public and private law. Since 1990's international entities and states have made rules to fight against private corruption. All of them advised to prosecute these reprehensible behaviors as a felony. In Colombia, a criminal law reform created corruption in the companies as a felony in 2011. This rule protects not only private interests of companies but also a public interest in the preservation of freedom in the market as well as rules governing unfair competition law.

KEY WORDS: Protected legal interest in private corruption felony, corruption in Colombia, economic crime, free market, unfair competition.

\footnotetext{
* Recibido: 29 de julio de 2014. Aceptado: 22 de septiembre de 2014.

* Profesor en la Facultad de Derecho y Ciencias Politicas de la Universidad de La Sabana, Bogotá, Colombia. (fernando.jimenez@unisabana.edu.co).

*** Profesora en la Escuela de Administración y en la Facultad de Relaciones Internacionales de la Universidad del Rosario, Bogotá, Colombia (maria.garciar@urosario.edu.co).
} 


\section{Sumario}

1. Introducción

2. Concepto de corrupción privada

3. Estrategias para combatir la corrupción privada

4. Tipificación del delito de corrupción privada en Colombia

5. El interés jurídico protegido en el delito de corrupción privada

6. Elementos para la integración sistemática y de conexión del delito de corrupción privada y la prohibición de comportamientos desleales en el derecho privado

7. Conclusiones

\section{Introducción}

El 15 de agosto de 2013, Pablo Muñoz, liquidador de la empresa Interbolsa, cuya quiebra representó uno de los mayores descalabros financieros en Colombia, afirmó:

La gente de Interbolsa no tenía ojos, sentimientos e intenciones distintas a trabajar para el grupo c. Y lo extraño es que del señor c. sólo tenemos una cédula de extranjería. Nunca le hemos conocido bienes a c., ni se los hemos podido conseguir.

La firma le entregó al italiano A. c. cerca de \$93.000 millones de pesos que fueron utilizados para el proceso de presunta especulación con la acción textilera Fabricato. El problema, reiteró el liquidador, es que las posibilidades de recuperación de ese dinero son bastante parecidas a cero. ${ }^{1}$

Recientemente, otro escándalo de corrupción en el sector empresarial, esta vez en Ecopetrol, la mayor empresa de hidrocarburos de Colombia, puso al descubierto problemas financieros de la empresa generados por conductas en donde habían prevalecido intereses particulares de los empleados sobre los intereses de la compañía.

En este sentido, a partir del escándalo mediático, la empresa emitió un comunicado a la opinión pública, afirmando:

Ecopetrol s. A. informa que ante las evidencias presentadas hoy por un medio de comunicación sobre consignaciones de F. E., directivo de la firma S., a una cuenta personal del señor R. E., ingeniero de la gerencia de soluciones integrales de transporte y logística de Ecopetrol, la empresa tomó la decisión de dar por terminado de forma inmediata su contrato de trabajo [...]. ${ }^{2}$

1 "Falta de moral acabó Interbolsa", en Revista Dinero, 15 de agosto de 2013.

2 Comunicado oficial de Ecopetrol, 19 de febrero de 2015. 
Los acontecimientos arriba mencionados ponen en evidencia situaciones de corrupción en el seno de las empresas, que terminan no solamente afectando a los propios accionistas, sino también al propio sistema económico y a la sociedad en general.

Desafortunadamente existen numerosos estudios y análisis que confirman la existencia de estas malas prácticas empresariales, no sólo a nivel nacional sino también internacional. ${ }^{3}$ Podríamos mencionar entre ellos el caso de la quiebra de la sociedad comisionista estadounidense Lehman Brothers, caso emblemático en cuanto, como es de público conocimiento, generó un efecto dominó en la pérdida de confianza en el sistema financiero, siendo el primer paso hacia la mayor crisis financiera internacional mundial desde 1929. Este caso, visto ya desde la perspectiva de algunos años, también tuvo su origen en la dudosa moralidad de las operaciones que se realizaban en perjuicio de los clientes inversores de la empresa comisionista.

Richard WolfF, en un artículo publicado en The Guardian, comentando el informe del 11 de marzo de 2010 sobre la quiebra de esta sociedad, señaló:

Lehman Brothers' bankruptcy has revealed multiple layers of ramifying corruption and theft among global banks in the us and elsewhere, as well. Many juicy details are covered in the nine-volume court examiner's report of 11 March 2010. It documents the bank executives' mammoth misjudgments in their investment decisions, including their repeated violations of the basic banking principle not to borrow short-term and lend the proceeds long-term. The bank examiner shows misleading statements made about their activities and how they disguised Lehman's financial health and credit-worthiness. It appears that various legal and semi-legal mechanisms were used to manipulate their accounts, and otherwise violate the spirit and letter of laws and regulations.

Of course, Lehman Brothers' top bank executives rewarded themselves stupendously while directing Lehman Brothers into collapse. In October 2008, the cEo of Lehman Brothers, Richard S Fuld, argued over pay with Congressman Henry Waxman during public hearings on the bankruptcy. Fuld insisted he had taken "only" $\$ 310 \mathrm{~m}$ in compensation during the seven years before 2008, whereas Waxman's figure was $\$ 485 \mathrm{~m}$. "Thieves," one can imagine Waxman muttering. ${ }^{4}$

Si bien la corrupción es un problema que ha trascendido en el tiempo, es en la actualidad cuando ha cobrado gran importancia, especialmente en entornos como el colombiano, que requieren de la máxima dinámica para avanzar en un proceso

\footnotetext{
${ }^{3}$ IONESCU, LUMINITA. "The Construction of Corruption as a Global Problem", en Contemporary Readings in Law and Social Justice, vol. 3 (1), 2011, pp. 166-171.

${ }^{4}$ Wolf, RICHARD. "Lehman Brothers: Financially and Morally Bankrupt", en The Guardian, 12 de diciembre de 2011.
} 
de desarrollo económico que garantice mejores condiciones para el bienestar de la población. ${ }^{5}$ Problemas como la corrupción hacen ineficiente el sistema económico y desvían recursos necesarios para inversión en infraestructuras, educación, alimentación y bienestar social de la población. ${ }^{6}$

Según el Índice de Percepción de Corrupción 2014 publicado por Transparency International (Іт), la percepción sobre la corrupción en el sector público de Colombia no presentó cambios significativos en el último año, obteniendo un puntaje de 37 sobre 100 (siendo 0 mayor percepción de corrupción y 100 menor percepción de corrupción), lo que la mantiene en el puesto 94 de entre los 175 países evaluados. Entre los 30 países americanos evaluados, Colombia sigue ubicándose por debajo del puntaje promedio de la región (45 sobre 100), siendo Chile el país mejor ubicado en América Latina (puesto 21 de la tabla, con 73 sobre 100) y Venezuela el peor (puesto 161 de la tabla, con 19 sobre 100).

De acuerdo con los resultados de la $13^{a}$ Encuesta Global sobre Fraude 2014 Ernst \& Young (EY), ${ }^{7}$ Colombia se encuentra en la sexta posición del listado entre 59 países (siendo el 1 el más corrupto), ocupando el primer puesto entre los países de América Latina. La encuesta permitió entrevistar a 2,700 ejecutivos, incluidos colombianos; el 40\% de ellos expuso que el soborno y la corrupción eran comunes en el sector empresarial.

Los empresarios que participaron en el estudio global consideraron que el fraude en el sector empresarial se da en todos los niveles. Por ejemplo, el 27\% de los presidentes de compañías estimó que el soborno ocurría de forma frecuente en su país. De igual manera, uno de cada 10 ejecutivos expuso que en los últimos dos años había tenido casos concretos en sus propias empresas.

En el caso particular de Colombia, el 71\% de los encuestados se refirió a la existencia de prácticas antiéticas, como ofrecer regalos personales para ganar o retener negocios, y alterar los resultados financieros de las compañías, entre otras prácticas.

La Encuesta refleja además que uno de los principales retos que deben afrontar las compañías es aumentar los esfuerzos por mitigar los riesgos de fraude de una forma más efectiva. En el caso de Colombia, la Encuesta mostró que el 60\% de los ejecutivos entrevistados no había participado en revisiones de cumplimiento sobre asuntos de anticorrupción o antisoborno en los últimos dos años; que el 45\% de las organizaciones no está mitigando los riesgos mediante

\footnotetext{
${ }^{5}$ Hoggard, Shlod. "Preventing Corruption in Colombia: The Need for an Enhanced State-Level Approach", en 21 Ariz J. Int'l \& Comp. L. 577, 2004.

6 KlitgaArd, Robert. Controlando la corrupción, Quipus, La Paz, 1992, 254 pp.

7 Disponible en: http://www.ey.com/Publication/vwLUAssets/EY-13th-Global-Fraud-Survey/\$FILE/EY-13th-GlobalFraud-Survey.pdf.
} 
la implementación de una línea ética, y que menos del 50\% había participado en entrenamientos de fraude, antisoborno y anticorrupción.

La información antes mencionada pone de relieve la importancia y gravedad de esta problemática en Colombia, y resalta, aún más, la creciente toma de conciencia y alarma que -tanto a nivel nacional como internacional- produce en la sociedad, haciendo cada vez más perentoria una intervención inmediata y más eficaz para prevenir y castigar este fenómeno, tanto en el ámbito público como privado.

En este sentido, las primeras investigaciones en materia de corrupción se orientaron hacia el estudio de las causas de este fenómeno en las sociedades contemporáneas. ${ }^{8}$ En este punto se ha llegado a la conclusión de que la corrupción no es un fenómeno exclusivo de países subdesarrollados, sino que afecta también al mundo desarrollado. ${ }^{9}$ Tradicionalmente se entendía que eran las condiciones de subdesarrollo económico las que promovían y alimentaban los fenómenos de corrupción. Sin embargo, estudios sobre la materia han llegado a la conclusión de que la corrupción se presenta igualmente en un entorno de desarrollo económico, por lo que se trata de un problema global al que deben enfrentarse todas las naciones, desarrolladas o no, al igual que la comunidad internacional.

Hoy en día, además del punto mencionado, es de especial interés académico el análisis de las formas de corrección y prevención de estas conductas. Desde esta perspectiva, se ha llegado a la conclusión de que la corrupción no es un fenómeno exclusivamente del Estado, sino que también se genera, con efectos perniciosos para toda la sociedad, al interior de las empresas. Surge así el concepto de corrupción "privada", paralelo al tradicional entendimiento de la corrupción "pública". Por otro lado, se llega a la convicción de que para combatir a la corrupción no sólo deben emplearse medidas de carácter correctivo sancionatorio, sino que es especialmente relevante implementar medidas preventivas.

La actuación del Estado y de la sociedad en la lucha contra este flagelo, si pretende obtener avances significativos, requiere la realización de actuaciones preventivas y sancionatorias que provengan de distintos ámbitos. En este sentido, la lucha contra la corrupción no puede hacerse exclusivamente desde el ámbito penal, como inicialmente se había concebido, sino que debe integrar medidas de gobierno y de derecho administrativo, al igual que otras actuaciones provenientes del derecho privado patrimonial. ${ }^{10}$

\footnotetext{
${ }^{8}$ Maldonado, Patricio y Berthin, Gerardo. "Transparency and Developing Legal Framework to Combat Corruption in Latin America", en 10 Sw. J. L. Et Trade Am. 243, 2003-2004, p. 247.

9 Sandgren, Claes. "Combating Corruption: The Misunderstood Role of Law", en 39 Int'l Law. 717, 2005.

10 Véase, al respecto, Bacigalupo, Enrioue. Derecho penal económico, Hammurabi, Buenos Aires, 2000, p. 11; Carbajo
} 
En el ámbito del derecho privado, la coordinación de normativas, como por ejemplo en el ámbito del derecho civil y comercial (particularmente en el derecho de la competencia, derecho de sociedades comerciales y la responsabilidad de los administradores), resulta claramente pertinente y puede brindar instrumentos muy efectivos para combatir la corrupción en el ámbito empresarial.

\section{Concepto de corrupción privada}

Cuando abordamos esta temática, el primer punto a analizar es el concepto de corrupción. ${ }^{11}$ Debemos encontrar en él un punto de referencia que nos sirva para conceptualizar este fenómeno en la totalidad de los ámbitos donde pretendemos analizarlo y estudiarlo. En este sentido, en general podemos afirmar que la corrupción implicaría una desviación ilícita del interés público o colectivo en beneficio de intereses privados.

En el ámbito privado podemos afirmar que la corrupción se refiere a comportamientos desviados de los centros de poder y de decisión en las empresas en beneficio de los administradores, empleados o personas cercanas a ellos, en detrimento de los intereses privados y colectivos de la empresa y en contra de las reglas que amparan el sistema de libre competencia.

Destacamos, en este sentido, la opinión de Fernando Carbajo CAscón, quien afirma que cada vez cobra más fuerza y sentido el análisis de la corrupción privada o corrupción en el sector privado, fruto de comportamientos desviados por parte de los centros de poder y decisión de las empresas privadas (administradores y cargos directivos laborales, como los apoderados, gerentes, directores generales o directores de área); empresas, por lo general, en forma de sociedad mercantil de capital (de ahí que en ocasiones se hable de corrupción corporativa), muchas de ellas grandes empresas con proyección pública (entidades y establecimientos financieros de crédito, empresas de servicios de inversión, sociedades cotizadas emisoras de valores, compañías de seguros, y empresas concesionarias de obras y servicios públicos, entre otras).

De acuerdo con Carbajo Cascón, ${ }^{12}$

CASCÓn, FERnAndo. "Corrupción en el sector privado (I): La corrupción privada y el derecho privado patrimonial", en IUSTITIA, 2012, p. 309.

11 Cocciolo, Endrius Euseo. "Las mutaciones del concepto de corrupción. De la ambigüedad de las sociedades arcaicas a la complejidad en la época del Estado regulador y de la sociedad del riesgo", en Revista de Llengua i Dret, núm. 50, noviembre de 2008, pp. 17-51.

12 Carbajo Cascón, Fernando. op. cit., p. 286. 
[...] estas desviaciones de intereses en la gestión de empresas privadas tienen lugar al aprovechar las lagunas legales y los defectos estructurales de las grandes compañías y del sistema financiero en su conjunto, en beneficio propio de los gestores o de personas relacionadas con ellos por relaciones familiares, de amistad, de confianza o por simple interés económico, y en detrimento de otros intereses privados particulares y colectivos (por ejemplo, los intereses de accionistas, inversores, trabajadores, acreedores, consumidores) y, a la postre, de los intereses generales cifrados en el funcionamiento eficiente del sistema financiero y económico en su conjunto.

\section{Estrategias para combatir la corrupción privada}

Los últimos años del siglo xx y principios del xxı han visto surgir distintas iniciativas para combatir el fenómeno de la corrupción privada. En muchos casos, la generalidad de los instrumentos propuestos se concentró en el establecimiento de códigos de buen gobierno y responsabilidad social empresarial; entendiendo así que, a pesar de no existir una normativa sobre la materia, la empresa, en su compromiso de responsabilidad social, debía elaborar estatutos y códigos de buen comportamiento que guiaran sus actuaciones en forma tal que se evitaran conductas corruptas al interior de las empresas y en sus relaciones comerciales con otros entes privados. ${ }^{13}$

Una de las acciones más interesantes encaminada a la prevención y lucha contra la corrupción es el Pacto Mundial (Global Compact), ${ }^{14}$ una iniciativa internacional propuesta por Naciones Unidas. Su objetivo es conseguir un compromiso voluntario de las empresas por medio de la implantación de diez principios basados en los derechos humanos, laborales, medioambientales y anticorrupción (este último aspecto se concreta en el principio 10 -"actuar contra todas las formas de corrupción, incluyendo la extorsión y el soborno"-, fundamentado en la Convención de las Naciones Unidas contra la Corrupción). De esta manera, las empresas que se adhieren al Pacto Mundial se comprometen a incorporar los diez principios en las actividades empresariales que la empresa realiza tanto en

\footnotetext{
${ }^{13}$ Bishop, Toby J. F. y Hrdoski, Frank E. Capacidad de recuperación empresarial, administración del creciente riesgo de fraude y corrupción, trad. de Samuel Mantilla, Ecoe Ediciones, Bogotá, 2010, 216 pp.

${ }_{14}$ El 24 de junio de 2004, durante la Cumbre de Lideres de Global Compact en Nueva York, se anunció que el Pacto Mundial de Naciones Unidas incluiría en adelante un décimo principio contra la corrupción. Esta decisión fue adoptada tras un proceso de consulta a todos los participantes, que expresaron su apoyo para luchar contra la corrupción. El principio 10 compromete a los firmantes del Pacto Mundial no solamente a evitar el soborno, la extorsión y otras formas de corrupción, sino también a desarrollar políticas y programas concretos que aborden el tema de la corrupción. Se les plantea a las empresas el reto de unirse a los gobiernos, agencias de la onu y a la sociedad civil por una economia global más transparente. Véase http://www.pactomundial.org/2015/04/principio-10/.
} 
el país de origen como en sus operaciones alrededor del mundo, y a presentar anualmente un informe de progreso sobre los avances en su implantación.

La insuficiencia manifiesta de mecanismos desde la misma empresa llevaron a la conclusión de la necesidad de establecer instrumentos desde el Estado que promovieran la prevención y sanción de los comportamiento corruptos a nivel privado. Fue de esta manera como el Estado, haciendo uso de sus poderes de intervención económica, empezó a promulgar normas que regularan estas materias.

Con este propósito, a nivel de derecho comunitario, derecho internacional y también derecho nacional, se empiezan a expedir diversos tipos de regulaciones. $^{15}$

En este sentido, la Unión Europea estableció un marco de referencia normativa en la Decisión marco 2003/568/JAl del Consejo, del 22 de julio de 2003, relativa a la lucha contra la corrupción en el sector privado. La Decisión promueve que la corrupción activa y pasiva en el sector privado sea un delito penal en todos los Estados miembros y que las personas jurídicas también puedan ser consideradas responsables de tales delitos.

Asimismo, estableció que "[...] los Estados miembros tomarán las medidas necesarias para asegurar que los siguientes actos intencionados constituyan una infracción penal cuando se lleven a cabo en el transcurso de actividades profesionales", definiendo estas conductas como:

a) Corromper a una persona:

[...] prometer, ofrecer o entregar, directamente o a través de un intermediario, a una persona que desempeñe funciones directivas o laborales de cualquier tipo para una entidad del sector privado, una ventaja indebida de cualquier naturaleza para dicha persona o para un tercero, para que ésta realice o se abstenga de realizar un acto, incumpliendo sus obligaciones.

b) Exigir una ventaja:

[...] pedir o recibir, directamente o a través de un intermediario, una ventaja indebida de cualquier naturaleza, o aceptar la promesa de tal ventaja, para sí mismo o para un tercero, cuando se desempeñen funciones directivas o laborales de cualquier tipo

${ }_{15}$ Garciandia Garmendia, Rosana. "La aplicación española de las normas de derecho internacional contra la corrupción", en Anuario Español de Derecho Internacional, vol. xxiv, 2008, pp. 241-269; Villoria, Manuel y Jiménez, Fernando. "La corrupción en España (2004-2010)", en Revista Española de Investigaciones Sociológicas, núm. 138, abril-junio de 2012, pp. 109-134. 
para una entidad del sector privado, a cambio de realizar o abstenerse de realizar un acto, incumpliendo sus obligaciones.

En este caso, el Consejo justifica la Decisión en que

[...] junto a la mundialización, los últimos años han traído un aumento del comercio transfronterizo de bienes y servicios, por lo que la corrupción en el sector privado de un Estado miembro ha dejado de ser un problema meramente interno para convertirse en un problema también transnacional, que se aborda más eficazmente mediante una actuación conjunta de la Unión Europea. ${ }^{16}$

De esta manera, la Unión Europea ha promulgado en los últimos años otras normas con la finalidad de crear un marco de gobernanza empresarial moderno, eficaz y comprometido con buenas prácticas, fundamentalmente dirigido hacia lo que considera deficiencias y/o problemas que facilitan la comisión de delitos de corrupción entre particulares, en especial la insuficiente implicación de los accionistas en la vigilancia y control de la empresa, y la falta de la transparencia en la gestión empresarial.

Destacamos las siguientes medidas que pretenden prevenir la ocurrencia de estas conductas:

- Comunicación de la Comisión del 4 de marzo de $2009^{17}$ que acompaña a la Recomendación de la Comisión que complementa las recomendaciones 2004/913/ce y 2005/162/cE en lo que atañe al sistema de remuneración de los consejeros de las empresas que cotizan en bolsa y a la Recomendación de la Comisión sobre las políticas de remuneración en el sector de los servicios financieros, donde se pone de manifiesto que la crisis financiera ha desvelado graves deficiencias en la forma en que se regulan y supervisan los mercados financieros.

- Comunicación de la Comisión “Europa 2020”, ${ }^{18}$ donde se reclama una mejora del entorno empresarial europeo como base de un entorno económico más fuerte y sostenible a largo plazo.

- El Libro Verde "El gobierno corporativo en las entidades financieras y las políticas de remuneración", ${ }^{19}$ de junio de 2010, en el cual la Comisión de-

\footnotetext{
${ }^{16}$ Benitez Ortuzar, Ignacio Francisco. "La ubicación entre los delitos de corrupción entre particulares. La Decisión marco 2003/568/JAl", El delito de fraudes deportivos. Aspectos criminológicos, político-criminales y dogmáticos del artículo 286 bis. 4 del Código Penal, Dykinson, Madrid, 2011, 202 pp.

17 com (2009) 114 final.

${ }^{18}$ Comunicación de la Comisión "Europa 2020: una estrategia para un crecimiento inteligente, sostenible e integrador", COM (2010) 2020 final.

19 com (2010) 284 final.
} 
fiende un sistema eficaz de gobierno corporativo a través de mecanismos de control y de contrapoderes que deberían procurar una mayor responsabilidad de los principales entes parte de las entidades financieras (consejos de administración, accionistas, direcciones, etcétera).

- El Libro Verde "La normativa de gobierno corporativo de la UE", ${ }^{20}$ de abril de 2011, donde la Comisión Europea considera que el gobierno corporativo y la responsabilidad social de las empresas son elementos clave para cimentar la confianza de las personas en el mercado único, y contribuye también a la competitividad de las empresas europeas.

- En este mismo sentido se encuentra el plan de acción de la Comisión "Derecho de sociedades europeo y gobierno corporativo. Un marco jurídico moderno para una mayor participación de los accionistas y la viabilidad de las empresas", ${ }^{21}$ donde se establece una hoja de ruta con el doble objetivo de aumentar la transparencia y propiciar la implicación de los accionistas, a partir de la aplicación del principio de "cumplir o explicar" como una metodología que hace a las empresas más responsables al fomentar la implantación y el cumplimiento de prácticas de gobierno corporativo adecuadas.

- Propuesta de Directiva del Parlamento Europeo y del Consejo, de abril de 2014, por la que se modifica la Directiva 2013/34/ve en lo que respecta a determinados elementos de la declaración sobre gobernanza empresarial, ${ }^{22}$ cuyo objetivo general es contribuir a la sostenibilidad a largo plazo de las empresas de la UE, configurar un entorno atractivo para los accionistas y aumentar la calidad del gobierno empresarial, elementos sustanciales que facilitarían una mejor gobernanza del sector privado y podrían evitar comportamientos corruptos dentro de ellas.

Paralelamente, en el ámbito internacional y comunitario andino han entrado en vigor los siguientes instrumentos:

- Convención de Naciones Unidas contra la Corrupción, del 31 de octubre de 2003: medidas para prevenir la corrupción, civiles, administrativas y penales. Ratificado por Colombia el 27 de octubre de 2006.

- Líneas Directrices de la oCDE para empresas multinacionales del año 2000.

- Pacto Mundial de Naciones Unidas, del 26 de julio de 2000, sobre responsabilidad empresarial.

\footnotetext{
${ }^{20} \operatorname{com}(2011) 164$ final.

$21 \operatorname{com}(2012) 740$ final.

22 com (2014) 213 final.
} 
- Convención Interamericana contra la Corrupción (1996), ratificada por Colombia el 25 de noviembre de 1998.

- Decisión 668 de la Comunidad Andina, que establece el Plan Andino de Lucha contra la Corrupción. ${ }^{23}$

El objetivo de muchas de las actuales normativas a nivel nacional en materia de transparencia es que exista un mayor control de los gestores que permita reducir el fenómeno de la corrupción y generar una mayor confianza de los ciudadanos en sus instituciones públicas y privadas.

El sector empresarial, consciente de la necesidad de prevenir y luchar contra conductas de corrupción, ha establecido en los últimos años, a través de algunas organizaciones internacionales gubernamentales y no gubernamentales, una serie de recomendaciones y normas que imponen obligaciones a los agentes privados.

La ong Transparencia Internacional lanzó en 2012 un Decálogo de Principios de Transparencia y Prevención de la Corrupción para Empresas con el objetivo de combatir los casos de corrupción en el sector privado. Éstos son:

1) Cumplimiento de los principios de buen gobierno corporativo (Código Unificado de Buen Gobierno Corporativo).

2) Implementación en la empresa de un código ético.

3) Implementación de programas de cumplimiento normativo (Compliance Programmes).

4) Creación de canales para denunciar el incumplimiento de normas.

5) Información pública de las retribuciones de los directivos y de los administradores.

6) Información de contrataciones y actividades subvencionadas.

7) Información pública de la políticas de responsabilidad social corporativa.

\footnotetext{
${ }^{23}$ Decisión 668 de la Comunidad Andina, Plan Andino de Lucha contra la Corrupción: "El Comité Ejecutivo Andino podrá presentar recomendaciones [...] 5. MEDIDAS DIRIGIDAS AL SECTOR PRIVADO: El Comité Ejecutivo Andino podrá presentar recomendaciones a los paises miembros sobre medidas que impidan el soborno a funcionarios públicos u otras prácticas de corrupción, a través de mecanismos de autorregulación del sector para asegurar, entre otros aspectos, que las empresas mantengan registros que reflejen con razonable detalle operaciones de contratación pública, adquisición y enajenación de activos y prácticas de competencia desleal. Promover la aplicación de mecanismos específicos de autorregulación corporativa para sancionar prácticas de corrupción dentro del sector privado, así como la expedición de códigos de ética, de conformidad con el ordenamiento jurídico interno de los paises miembros. Impulsar la elaboración de un registro de empresas y empresarios comprometidos en actos de corrupción, incluyendo las sanciones aplicables a los mismos, y la difusión de este registro, de acuerdo a lo establecido en las normas nacionales e internacionales en la materia. Promover mecanismos de acceso a la información en poder de entidades del sector privado, cuando presten servicios públicos o reciban o administren recursos públicos, de acuerdo a lo establecido en las legislaciones nacionales".
} 
8) Evitación de prácticas de favorecimiento y corrupción en el sector privado.

9) Evitación de prácticas de corrupción de funcionarios extranjeros en las transacciones internacionales.

10) Cumplimiento de las obligaciones fiscales.

\section{Tipificación del delito de corrupción privada en Colombia}

Como hemos comentado, las normativas internacional, comunitaria europea y también andina se han orientado al establecimiento de un conjunto de normas de naturaleza diversa, cuya finalidad es prevenir y sancionar comportamientos corruptos al interior de la empresa.

En este ámbito resulta de especial relevancia la normativa penal que tipifica el delito de corrupción privada. En este sentido, como hemos visto, las distintas iniciativas de derecho comunitario e internacional hacen énfasis en la necesidad de establecer tipos penales que sancionen este tipo de conductas.

En Colombia, la normativa que consagró este delito entró en vigencia en 2011, incorporando la conducta bajo el título VIl (Delitos contra el patrimonio económico), capítulo $\vee$ (Abuso de confianza), artículo 250-A, de la siguiente forma:

El que directamente o por interpuesta persona prometa, ofrezca o conceda a directivos, administradores, empleados o asesores de una sociedad, asociación o fundación una dádiva o cualquier beneficio no justificado para que le favorezca a él o a un tercero, en perjuicio de aquélla, incurrirá en prisión de cuatro (4) a ocho (8) años y multa de diez (10) hasta mil (1.000) salarios mínimos legales mensuales vigentes.

Con las mismas penas será castigado el directivo, administrador, empleado o asesor de una sociedad, asociación o fundación que, por sí o por interpuesta persona, reciba, solicite o acepte una dádiva o cualquier beneficio no justificado, en perjuicio de aquélla.

Cuando la conducta realizada produzca un perjuicio económico en detrimento de la sociedad, asociación o fundación, la pena será de seis (6) a diez (10) años.

Como puede observarse en la estructura del delito, se realizó una tipificación similar a la del delito de cohecho, en el cual participan agentes públicos. En este caso se refiere a conductas que se desarrollan en el ámbito estrictamente privado, en el cual no hay una relación objetiva ni subjetiva con la causa pública. Ningún implicado reúne la condición de funcionario público ni custodia o gestiona fondos públicos. 


\section{El interés jurídico protegido en el delito de corrupción privada}

Uno de los puntos a examinar en el análisis de esta nueva normativa penal es el relativo al interés jurídico protegido. Ello es relevante como criterio de interpretación del tipo penal a efecto de verificar si una determinada conducta queda incursa en la norma tipificada. Particularmente se pregunta si para que una conducta sea sancionada penalmente por corrupción privada se exige que produzca una afectación al patrimonio de la empresa, o si basta con que se afecten los intereses comunes, particularmente el sistema de libre competencia.

En este sentido, son diversos los modelos adoptados a nivel internacional. Alemania, Austria y Suiza siguen un modelo que basa el tipo penal en la afectación de un interés general.

Como veremos más adelante, la sanción por comportamientos corruptos al interior de la empresa provino inicialmente, como sucede en Alemania, de las normas de derecho de la competencia desleal.

Se entendía que esta clase de comportamientos afectaba ante todo el sistema de libre competencia, en la medida en que los particulares debían, al igual que los funcionarios públicos, atender a la protección de los intereses generales, en este caso la estructura del sistema.

Consecuencia de esta concepción es que el interés protegido en este tipo de delitos es ante todo el interés general.

Por el contrario, otros países, como es el caso de Francia, Bélgica y Reino Unido, entienden que estos comportamientos afectan ante todo los intereses privados de la empresa que sufre los efectos de la conducta corrupta. ${ }^{24} \mathrm{Un}$ comportamiento de esta naturaleza por parte de un empleado de la empresa constituye una vulneración a su deber de lealtad y fidelidad a la empresa. ${ }^{25}$ Desde esta perspectiva, la realización de la conducta típica supone la causación de un perjuicio a la empresa con la cual se está laborando, en ausencia del cual no puede considerarse delito alguno.

Los alcances de uno y otro modelo son diversos. Resta, en este sentido, por estudiar a cuál de los dos sistemas atiende la regulación establecida en el artículo 250-A del Código Penal colombiano, punto que examinaremos en el siguiente

\footnotetext{
${ }^{24}$ Benavides Schiller, Andrés. "Acerca de la corrupción pública y privada en España a la luz de los delitos contra la administración pública (título xix del libro ॥ cP español)", en Cuadernos de Política Criminal, segunda época, núm. 108, diciembre de 2012, pp. 119-139.

${ }^{25}$ Como sucede en el caso de los delitos de administración desleal. Fejuo Sánchez, Bernardo. Cuestiones actuales de derecho económico, Editorial B de F, Buenos Aires, 2009, p. 261; Martinez-Buján Pérez, Carlos. Derecho penal económico, Tirant lo Blanch, Valencia, 2002, p. 106.
} 
epígrafe, vinculándolo a la regulación que también sobre la materia tiene la legislación sobre competencia desleal. ${ }^{26}$

\section{Elementos para la integración sistemática y de conexión del delito de corrupción privada y la prohibición de comportamientos desleales en el derecho privado}

Una conducta de corrupción privada, como hemos mencionado, puede tener tratamientos distintos en el mundo del derecho. Una de las características que vive el mundo contemporáneo es el derribo de fronteras que tradicionalmente separaban el orden nacional del internacional. Este fenómeno se presenta igualmente entre las distintas ramas del derecho, que deben interpretarse y aplicarse complementaria y coordinadamente. Este es el caso que examinamos.

Para poder entender el alcance jurídico del interés protegido en el delito de corrupción es conveniente también examinar la materia a la luz del ordenamiento protector y regulador, en este caso proveniente del derecho privado, de la competencia desleal. No debemos olvidar que tanto la regulación penal como la de competencia desleal pretenden proteger el sistema de economía de mercado. Un breve análisis sobre la materia en el ámbito de la competencia desleal nos brindará, como veremos, algunas luces y semejanzas que serán de utilidad para la interpretación del delito de corrupción privada.

El adecuado funcionamiento de la economía de mercado requiere de la presencia de instituciones que garanticen la transparencia y la corrección de las actuaciones competitivas de los operadores económicos.

El desarrollo económico del sistema capitalista se basa en la existencia de una competencia permanente entre los distintos operadores económicos con la finalidad de captar una cada vez mayor cuota de mercado. Desde este punto de vista, deben ser el ingenio, la adaptación, la creatividad y la calidad de los productos que se ofrecen por los empresarios los criterios que deben guiar al consumidor en la elección de los productos o servicios, determinando igualmente qué empresarios deben mantenerse y cuáles deben desaparecer del mercado.

La evolución del sistema económico hacia estadios más avanzados y cada vez más globales ha puesto en evidencia la necesidad actual de proteger la economía de mercado. Si bien en un momento inicial de regulación económica

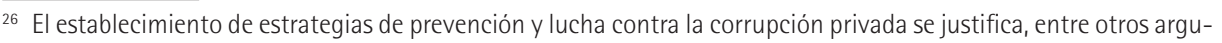
mentos, en garantizar el respeto a la competencia equitativa y leal, ya que este fenómeno distorsiona las reglas de la competencia respecto de la adquisición de bienes o servicios comerciales e impide un desarrollo económico sólido. Otero, PILAR. "Corrupción entre particulares (delito de)", en EUnOMIA, núm. 3, septiembre de 2013, p. 175.
} 
las doctrinas liberales clásicas entendían que el sistema de economía de mercado no requería ninguna intervención por parte del Estado, puesto que sus leyes automáticamente corregirían cualquier desviación, pronto, con el devenir histórico y la experiencia misma en la aplicación del modelo, se hizo evidente que en la práctica se presentaban distorsiones que debían ser ajustadas para la supervivencia del sistema.

En este sentido, doctrinas económicas que surgen a lo largo del siglo XIX ya exigían una intervención por parte del Estado con la finalidad de ajustar las actuaciones que realizan los empresarios a criterios de lealtad, corrección y buena fe en la competencia por cuotas de mercado.

A partir de estas concepciones se puede entender que no toda conducta empresarial en términos de competencia es válida, sino que debe ajustarse a un juicio de corrección y moralidad en los negocios. El sistema de economía de mercado debe premiar el esfuerzo empresarial cuando éste se basa en condiciones de lealtad y eficiencia, y debe, por otro lado, no permitir y sancionar aquellas conductas que se alejen de criterios de corrección en los negocios, tanto desde el derecho de la competencia como del derecho penal.

Tolerar estas conductas, contrarias a las buenas costumbres mercantiles, generaría una distorsión en la competencia afectando la economía de mercado, permitiendo que no sean los mejores operadores del mercado los que prevalezcan, sino aquellos otros que basados en actuaciones tortuosas terminen imponiéndose.

En este sentido, la evolución misma de las ideas protectoras del sistema permitió la integración de reglas de derecho comercial que atendieran a las finalidades mencionadas, inicialmente reconocidas a nivel jurisprudencial a través de la estructura de la responsabilidad extracontractual (caso francés), y posteriormente a través de la promulgación de leyes especiales, como la ley alemana del 7 de junio de $1909 .{ }^{27}$

En ambos casos se otorgaban acciones a aquellos competidores que se vieran afectados por los comportamientos desleales para protegerse de estas conductas. En este sentido, y como es apenas natural, se entendía que sólo aquellas conductas que afectaban de manera directa a un competidor en el mercado podían ser objeto de rechazo y sanción jurídica. Por el contrario, cuando no se presentara esta relación de competencia directa, aunada a un perjuicio patrimonial en contra del ofendido, no podía entenderse ninguna infracción al deber de respeto a la competencia leal.

27 Bercovitz Rodriguez-Cano, Alberto. Apuntes de derecho mercantil, Aranzadi, Pamplona, 2000, p. 316. 
Posteriormente, con el advenimiento de las doctrinas protectoras del derecho antitrust norteamericano en la época de la posguerra (a partir de la década de los años cincuenta del siglo xx), el derecho que protege la libre competencia adquiere una dimensión más amplia.

El movimiento en el terreno de las ideas que estableció los nuevos criterios orientadores de la materia situó la base del sistema no en la afectación de uno o varios competidores en concreto, como era tradicional en la competencia desleal, sino en la necesidad de proteger la economía de mercado, ampliando considerablemente su contenido hacia la protección del interés general. ${ }^{28}$

Veremos así cómo, por ejemplo, en la regulación de la competencia desleal vigente en Colombia, establecida en la Ley 256 de 1996, se integra esta visión que no solamente descansa en los intereses de uno o varios comerciantes, sino también en la necesidad de proteger el interés social a través de la corrección de comportamientos que puedan afectar el sistema económico de mercado.

De esta forma, la normativa sobre competencia desleal actualmente vigente se orienta a examinar las conductas de los operadores económicos en el mercado y a prohibirlas y sancionarlas en caso de que siendo incorrectas causen o puedan causar un perjuicio a otros participantes en el mercado, o bien puedan afectar o distorsionar el funcionamiento propio del sistema competitivo.

En este sentido, el artículo 2 de la Ley de Competencia Desleal en Colombia establece que:

\footnotetext{
${ }^{28}$ Indudablemente que la economía de guerra de los países involucrados en las dos guerras mundiales abrió la posibilidad en el establecimiento de una política intervencionista en la economía, cuya finalidad última, en el marco de las dos guerras mundiales, era garantizar la existencia de adecuadas condiciones industriales y económicas que permitieran un suministro adecuado a los frentes de batalla, indispensable para lograr una victoria. De esta manera, los Estados europeos aprendieron las bondades de la intervención en la economía, superando los esquemas liberales que hasta ese momento prevalecian, basados en la doctrina del laissez faire, laissez passer, que negaba la necesidad de intervenir en la economía por cuanto la libertad de los actores económicos generaría naturalmente las condiciones de máxima eficiencia y desarrollo económico en el sistema.

El conflicto bélico trajo consigo, además de los mecanismos para la intervención en la economía, un cuestionamiento sobre la conveniencia de dejar completamente en libertad a los actores económicos en sus actividades de mercado. La necesidad manifiesta de orientar la economía y corregir aquellos excesos que pudieran afectar el sistema de mercado y el interés general creó el ambiente adecuado para la conformación de un nuevo derecho cuya finalidad era la protección del sistema competitivo, denominado - desde su origen estadounidense- derecho antitrust.

Si bien las instituciones jurídicas de este nueva normativa se orientaban principalmente a prohibir cualquier acuerdo o conducta asociada de operadores económicos con la finalidad de restringir o impedir la competencia en el mercado, conformando el nuevo derecho antitrust, también esta original perspectiva tuvo una influencia directa en las instituciones que hasta entonces regulaban los comportamientos individuales de los empresarios en el mercado en el marco del tradicional derecho de la competencia desleal y también del derecho penal. Las normas de competencia desleal y las jurídico-penales que hasta ese momento protegían exclusivamente a empresarios cuando se vieran afectados por comportamientos desleales de otros empresarios, amplían su marco de acción para comprender también todos aquellos comportamientos desleales que afecten el sistema de economía de mercado, protegiendo así un interés general.
} 
Los comportamientos previstos en esta ley tendrán la consideración de actos de competencia desleal siempre que se realicen en el mercado y con fines concurrenciales.

La finalidad concurrencial del acto se presume cuando éste, por las circunstancias en que se realiza, se revela objetivamente idóneo para mantener o incrementar la participación en el mercado de quien lo realiza o de un tercero.

\section{Por su parte, el artículo 3 de la Ley de Competencia Desleal afirma:}

Esta ley se le aplicará tanto a los comerciantes como a cualesquiera otros participantes en el mercado.

La aplicación de la ley no podrá supeditarse a la existencia de una relación de competencia entre el sujeto activo y el sujeto pasivo en el acto de competencia desleal.

Los mencionados artículos definen lo que se denomina ámbitos objetivo y subjetivo de aplicación de la normativa de competencia desleal. ${ }^{29}$

Una vez entendido cuándo un acto es de competencia o concurrencial, procede su revisión para verificar que dicho acto se ajusta a los parámetros de lealtad y corrección establecidos en el ordenamiento jurídico, que en el caso de la ley colombiana se integra a través del establecimiento de una cláusula general prohibitiva (artículo 7) completada con un listado no exhaustivo de comportamientos que se consideran desleales a efectos de su prohibición y sanción. ${ }^{30}$

\footnotetext{
${ }^{29}$ El primer punto a dilucidar, en lo que se refiere al ámbito objetivo de aplicación, es qué actos pueden considerarse de competencia, en expresión de la ley "concurrenciales". De acuerdo con el artículo 2 antes mencionado, un acto es de competencia cuando es objetivamente idóneo para mantener o incrementar la participación en el mercado de quien lo realiza, o de un tercero. En este sentido, toda acción de operadores económicos, utilizando diversos mecanismos, que objetivamente pretendiera mantener o incrementar su participación en el mercado se considera acto de competencia o concurrencial. Son actos de competencia, por ejemplo, la publicidad de la empresa, así como cualquier decisión o actuación de cualquier naturaleza que tenga por finalidad alterar a su favor o de un tercero la participación en el mercado. Debemos observar cómo la ley, para la definición de acto de competencia o concurrencial, no requiere una relación directa entre dos o más comerciantes, como ocurría en las primeras regulaciones sobre la materia. El acto se revela de competencia incluso en ausencia de que se oriente a afectar a un empresario competidor en particular; basta con que pretenda obtener el mantenimiento o una mayor cuota de mercado, dirigido en este caso a todos aquellos que participan en el mismo. Se tiene en cuenta, por tanto, no solamente el interés de los comerciantes particulares en la protección de su patrimonio individual, sino especialmente la protección del interés general en mantener la economía de mercado y promover la sana competencia entre los distintos actores económicos. Por otro lado, el artículo 3 de la Ley de Competencia Desleal establece que "esta ley se le aplicará tanto a los comerciantes como a cualesquiera otros participantes en el mercado". El establecimiento de esta regla constituye un importante logro demandado en las normas de competencia que tienen vocación de aplicarse a las actuaciones de cualquier operador económico sin consideración a si es comerciante o empresario. Sin duda alguna que este criterio amplía significativamente el ámbito de aplicación de las normas de competencia desleal, impidiendo que consideraciones formales (el reconocimiento de la calidad de comerciante) puedan obstaculizar la persecución de actos claramente desleales o incorrectos para el sistema.

30 Existen diversos sistemas para establecer que un acto de competencia es desleal. Una posibilidad es acudir al sistema de listado y tarifa legal para integrar los comportamientos que normalmente son desleales. A pesar de la
} 
La legislación de competencia desleal es de esta manera otro mecanismo de derecho privado idóneo para perseguir las conductas constitutivas de corrupción privada. ${ }^{31}$ Indudablemente que la actuación de un empresario que ofrece a un empleado o subordinado de una empresa una ventaja injustificada para obtener un favor constituye un acto desleal prohibido en el marco de esta regulación y susceptible de las sanciones y remedios que correspondan.

Sin embargo, en el análisis que estamos realizando es particularmente importante la visión de esta materia por cuanto nos ayuda a una interpretación adecuada del artículo 250-A del Código Penal colombiano que tipifica el delito de corrupción privada.

En este sentido, a pesar de que la mencionada norma está -como lo hemos comentado- inserta en el título que corresponde a los "Delitos contra el patrimonio económico", capítulo "Abuso de confianza", y por lo tanto se podría entender que atiende al interés de otro empresario, la orientación general de la legislación, no solamente en materia de derecho penal sino incluso en derecho privado, particularmente el derecho de la competencia, cuando regula estos casos como hemos visto, se orienta a proteger el interés general de mantenimiento del mercado. ${ }^{32}$

Una conducta constitutiva del delito de corrupción privada no solamente atenta contra el interés particular de un(os) determinado(s) comerciante(s), sino que se protege intereses generales de mantenimiento del sistema de libre competencia. ${ }^{33}$ Puede en este sentido aplicarse este tipo penal incluso si no se llega

aparente seguridad que ofreceria un sistema así, no cabe duda que implicaria una excesiva rigidez que impediria realizar el juicio de deslealtad sobre actos nuevos o aún no contemplados por el legislador. De esta manera, la legislación colombiana en materia de competencia desleal ha acudido, en primera instancia, al sistema de cláusula general prohibitiva basado en un modelo comparativo con las buenas costumbres, los usos honestos o las normas de corrección en material industrial o comercial. De esta manera, sería desleal todo acto concurrencial que sea contrario a los criterios que nuestro ordenamiento jurídico entiende como contrarios a las buenas costumbres, los usos honestos o las normas de corrección en materia industrial y comercial. Esta cláusula general, como hemos dicho, se complementa con un listado no exhaustivo de actos que se consideran tradicionalmente como desleales.

31 Bora, Alexandrina-August. "About Corruption within the Public-Private Partnership", en Agora International Juridical Science, 30, 2008, p. 30; Encinar del Pozo, Miguel Ángel. "La transparencia de las relaciones mercantiles y la reforma del Código Penal de 2010", en Cuadernos de Política Criminal, segunda época, núm. 103, mayo de 2011, pp. 169-194.

32 De manera similar al caso del derecho español. Pérez Ferrer, Fátima. "Aspectos dogmáticos y político-criminales de la protección del mercado, la competencia y los consumidores en el derecho penal", Derecho y consumo. Aspectos penales, civiles y administrativos, abril de 2013.

33 "Dentro de un Estado social de derecho, cada sujeto tiene una función económica distinta, cuya realización dentro del ámbito de la libertad económica es el objeto tutelado por el derecho penal: los empresarios se encargan de la producción, distribución y comercialización de bienes y servicios; los consumidores realizan una adquisición justa de los mismos y el Estado está encargado del cumplimiento de los fines sociales que le son propios en beneficio de los intereses comunitarios. Por ello, el bien jurídico tutelado en los delitos económicos se debe identificar con la libertad económica en el marco del Estado social de derecho, cuyo ejercicio se concreta en los presupuestos (materiales, legales, económicos e informativos) para la participación libre de todos los actores económicos dentro del sistema económico. La libertad económica no puede equipararse sólo con la ausencia de monopolios económicos 
a afectar patrimonialmente a una empresa en particular. En caso de que se produzca esta afectación, sin duda alguna se incurre en el delito con circunstancias de agravación punitiva.

\section{Conclusiones}

Primera. Los estudios e investigaciones actuales muestran que la corrupción no es un fenómeno exclusivo de países subdesarrollados, sino que afecta significativamente a toda la comunidad internacional (entre ellos, también los países con economías desarrolladas). Igualmente se percibe como uno de los grandes problemas actuales contra los que hay que actuar de forma coordinada tanto en los niveles puramente nacionales como internacionales y de integración económica.

Segunda. La corrupción es un problema particularmente importante para la sociedad colombiana y también latinoamericana, decidida a avanzar en un proceso de desarrollo, prosperidad y bienestar social, constituyendo este flagelo un lastre que dificulta y en ocasiones impide la realización de estos objetivos.

Tercera. La lucha contra la corrupción exige la utilización de diversos instrumentos en el ámbito del derecho, no solamente provenientes del derecho penal, sino también desde el ámbito del gobierno corporativo, del derecho administrativo y del derecho privado patrimonial. En este último ámbito es cada vez más relevante el concepto de corrupción privada en el seno de las empresas.

Cuarta. Se entiende por corrupción privada aquella desviación del poder de decisión en el seno de las empresas en beneficio de los administradores, empleados o personas cercanas a ellos y en detrimento de los intereses privados y colectivos de la empresa y de las reglas que amparan el sistema de libre competencia.

Quinta. En la lucha contra la corrupción privada se han implementado diversos instrumentos, particularmente a partir de la primera década de este siglo. Estos instrumentos se integran en iniciativas de derecho internacional, dentro de las cuales debemos destacar la Convención de las Naciones Unidas contra la Corrupción (2003) y la Convención Interamericana contra la Corrupción (1996). En el ámbito jurídico comunitario de la Unión Europea se han producido diversas acciones comunes, recomendaciones y decisiones sobre la materia, así como también en el derecho de la Comunidad Andina, en donde se ha enunciado un Plan Andino contra la Corrupción.

o de restricciones a la libertad de empresa, sino en general con la ausencia de cualquier obstáculo que afecte las actuaciones económicas en el mercado (las empresas, los consumidores y el Estado), tales como el error, la coacción, el engaño, la incapacidad y la inclusión de objetos ilícitos en el sistema económico [...]". Castro Cuenca, Carlos Guillermo y Ramirez Barbosa, Paula Andrea. Derecho penal económico, parte general, Grupo Editorial Ibáñez, Bogotá, 2010, p. 96. 
Sexta. Todos estos instrumentos internacionales sugieren la idea de establecer como mecanismos de actuación la consagración de tipos penales de corrupción privada; normas que promuevan un mejor gobierno corporativo empresarial; mayor transparencia en el gobierno de la empresa; limitación y control a la actividad de gestión al interior de la empresa; responsabilidad penal de las personas jurídicas, y modificación en la responsabilidad de los administradores de sociedades comerciales.

Séptima. Una modificación del Código Penal colombiano en 2011 permitió la consagración del delito de corrupción privada, entendiéndose como conducta penal el ofrecer a administradores, empleados o asesores de empresas, beneficios no justificados para obtener un trato de favor a él o a un tercero, en perjuicio de los intereses de la empresa. También es sancionable por vía penal el recibir beneficios no justificados por otorgar tratos a favor.

Octava. La elaboración de este nuevo tipo penal se hizo a semejanza del delito de cohecho; sin embargo, en este caso, en ausencia de intervención de un funcionario público.

Novena. A pesar de que el tipo penal se encuentra en el título vil (Delitos contra el patrimonio económico), capítulo $\vee$ (Abuso de confianza), el interés jurídico protegido no es exclusivamente el interés de la empresa que puede resultar perjudicada, sino que también se protege el interés general en el mantenimiento del libre mercado. Al igual que sucede en el ámbito de la competencia desleal, una conducta de corrupción privada afecta seriamente el principio de libre competencia y se prohíbe y sanciona, también en el ámbito penal, aun en ausencia de la generación de un perjuicio para una determinada empresa. En este caso, la producción de este perjuicio constituye circunstancia de agravación del delito. 